\title{
Utility of high-sensitivity cardiac troponin T in patients receiving anthracycline chemotherapy
}

\author{
This article was published in the following Dove Press journal: \\ Vascular Health and Risk Management \\ 24 November 2015 \\ Number of times this article has been viewed
}

\section{Anne H Blaes' \\ Aamer Rehman ${ }^{2}$ \\ David M Vock ${ }^{3,4}$ \\ Xianghua Luo $^{3,4}$ \\ Mark Menge ${ }^{5}$ \\ Douglas Yee $^{3}$ \\ Emil Missov ${ }^{6}$ \\ Daniel Duprez ${ }^{6}$}

'Division of Hematology/Oncology/ Transplantation, Department of Medicine, University of Minnesota, Minneapolis, MN, ${ }^{2}$ Division of Cardiology, University of Louisville, Louisville, KY, ${ }^{3}$ Masonic Cancer Center, ${ }^{4}$ Division of Biostatistics, School of Public Health, University of Minnesota, Minneapolis, ${ }^{5}$ Park Nicollet Frauenshuh Cancer Center, St Louis Park, ${ }^{6}$ Division of Cardiology, Department of Medicine, University of Minnesota, Minneapolis, MN, USA

Correspondence: Anne H Blaes Division of Hematology/Oncology/ Transplantation, Department of Medicine, University of Minnesota, 420 Delaware

Street Southeast - MMC 480,

Minneapolis, MN 55455, USA

Tel + I 612 6268138

Email blaes004@umn.edu
Background: Anthracycline chemotherapy remains an integral part of the care for curative intent chemotherapy in breast cancer and non-Hodgkin lymphoma patients. Better tools need to be identified to predict cardiac complications of anthracycline chemotherapy.

Materials and methods: We investigated the utility of high-sensitivity cardiac troponin $\mathrm{T}$ (hscTnT), N-terminal pro-B-type natriuretic peptide, cardiac troponin $\mathrm{T}$ and $\mathrm{I}$, and creatine kinase (CK)-MB in cancer patients receiving anthracycline-based chemotherapy, in order to determine whether baseline levels or changes in these biomarkers may help predict the onset of congestive heart failure.

Results: Eighteen consecutive patients with a pathologic diagnosis of breast cancer or nonHodgkin lymphoma were enrolled. The median dose of doxorubicin exposure was $240 \mathrm{mg} / \mathrm{m}^{2}$ (range 240-400 mg/m²). After treatment with doxorubicin, the hscTnT increased to $19.1 \mathrm{pg} / \mathrm{mL}$ $(P<0.001)$. CKMB and N-terminal pro-B-type natriuretic peptide levels increased to $1.1 \mathrm{ng} / \mathrm{mL}$ and $88.3 \mathrm{pg} / \mathrm{mL}$, respectively $(P=0.02)$. When subjects who had a decline in left ventricular ejection fraction (LVEF) by equilibrium radionuclide ventriculography were compared to those who did not have a change in LVEF, there was a suggestion that those subjects with an elevated baseline hscTnT were more likely to have a decline in LVEF $(2.7 \mathrm{pg} / \mathrm{mL}$ and $0.1 \mathrm{pg} / \mathrm{mL}$, respectively; $P=0.07)$. Spearman correlation demonstrated that patients with higher baseline hscTnT and CKMB tended to have a greater decline in LVEF (Spearman correlation -0.54 , $95 \%$ confidence interval -0.80 to $-0.08[P=0.02]$, and $-0.49,95 \%$ confidence interval -0.77 to $-0.01[P=0.04]$, respectively).

Conclusion: Elevations in baseline hscTnT levels are suggestive of an oncology subgroup at high risk of developing cardiac complications from their chemotherapy. Early detection by oncologists with the use of baseline biomarkers may be clinically important in designing interventions to prevent serious anthracycline-based chemotherapy complications.

Keywords: troponin T, doxorubicin, cardiomyopathy, chemotherapy

\section{Background}

There is an unmet need for the early detection of cardiovascular damage in cancer survivors treated with potentially cardiac toxic medications. ${ }^{1}$ Current practice relies on the use of left ventricular ejection fraction (LVEF) to document the myocardial impact of doxorubicin. These techniques are insensitive. ${ }^{1-3}$ With the development of highly sensitive troponins, more attention has been focused on the predictive value of cardiovascular disease beyond the diagnostic usage for acute coronary syndrome. ${ }^{4-6}$ Studies of the general population suggest that those with an elevation in their cardiac troponin are associated with an increase in cardiovascular mortality. ${ }^{7,8}$ Those individuals with an elevation in their cardiac troponin during the receipt of chemotherapy 
have also been associated with permanent changes in LVEF. ${ }^{9}$ Other studies are ongoing using B-natriuretic peptide (BNP) as predictors of cardiac events. We present a small pilot study designed to evaluate whether baseline biomarkers or changes in these biomarkers predict cardiac damage in those patients receiving doxorubicin chemotherapy.

\section{Materials and methods}

We evaluated levels of N-terminal (NT)-proBNP, cardiac troponin T (cTnT), cTnI, and high-sensitivity (hs)-cTnT in 18 consecutive cancer patients $>18$ years with a diagnosis of breast cancer $(n=14)$ or non-Hodgkin lymphoma $(n=4)$ receiving anthracycline-based chemotherapy, in order to determine whether baseline levels or changes in these markers (at each follow-up chemotherapy and at 4 weeks following the completion of chemotherapy) may help predict the onset of heart failure. All patients provided written informed consent. The Institutional review board at the University of Minnesota approved this study. All patients were treated at the University of Minnesota Masonic Cancer Center.

All patients underwent equilibrium radionuclide ventriculography (multigated acquisition) in the best septal view after in vivo labeling of red blood cells with technetium$99 \mathrm{~m}$ pertechnetate for determination of LVEF prior and 4 weeks after the completion of doxorubicin chemotherapy (E-Cam gamma camera; Siemens AG, Berlin, Germany). While ultrasound cardiography is growing in clinical use, multigated acquisition was the preferred practice at the time of this study. All patients underwent blood draws to evaluate NT-proBNP, cTnT, cTnI, and hscTnT at baseline, before each cycle of chemotherapy and 4 weeks after the completion of chemotherapy. The analytical sensitivity of the cTnI was $0.03 \mathrm{ng} / \mathrm{mL}$. cTnT, hscTnT, and NT-proBNP were measured on an Elecsys 1010 platform (Hoffman-La Roche Ltd, Basel, Switzerland). The analytical sensitivity of the cTnT, hscTnT, and NT-proBNP immunoassays was $0.010 \mathrm{ng} / \mathrm{mL}, 1 \mathrm{pg} / \mathrm{mL}$, and $3 \mathrm{pg} / \mathrm{mL}$, respectively. Measurements of all biomarkers were performed without knowledge of clinical or LVEF data.

Summary statistics were calculated for all baseline, follow-up, and changes in markers of cTnI, cTnT, hscTnT, NT-proBNP, and LVEF. Patients were followed for up to 4 weeks following the completion of their chemotherapy. Paired $t$-test or Wilcoxon signed-rank test was used for comparing baseline and follow-up markers. $t$-Tests or Wilcoxon rank-sum tests were also used to compare the markers of those with and without declines in LVEF. Spearman correlation was calculated for the change (ie, follow-up minus baseline) in LVEF with baseline and follow-up biomarker values. $P<0.05$ was considered statistically significant.

\section{Results}

A total of 18 patients (16 female, two male) with a median age of 52 years (range 30-72 years) received combination anthracycline-based chemotherapy with a median dose of doxorubicin exposure of 240 (range 240-402) $\mathrm{mg} / \mathrm{m}^{2}$. All subjects had normal liver and kidney function and no cardiac history. Mean systolic blood pressure was $124.5 \pm 14.8 \mathrm{mmHg}$, while mean diastolic blood pressure was $75.5 \pm 9.4 \mathrm{mmHg}$. Fourteen of 18 patients received therapy for breast cancer; the remainder received chemotherapy for non-Hodgkin lymphoma. No patients received mediastinal radiation. All patients received combination chemotherapy (with cyclophosphamide in those with a diagnosis of breast cancer, and with cyclophosphamide, vincristine, and prednisone in those with a diagnosis of non-Hodgkin lymphoma). No clinical cardiac events were observed during the chemotherapy or within 4 weeks of completing chemotherapy. The median LVEF at baseline was 58\% (range 50\%-70\%). cTnI and cTnT were not detectable at baseline. The median hscTnT at baseline was $1.39 \mathrm{pg} / \mathrm{mL}$. The median NT-proBNP was $46.1 \mathrm{pg} / \mathrm{mL}$ (range 28.2-383.4 pg/mL).

Baseline and follow-up variables are outlined in Table 1. Following treatment with doxorubicin, hscTnT increased significantly to $19.1 \mathrm{pg} / \mathrm{mL}$ (range $0.8-77.2 \mathrm{pg} / \mathrm{mL})(P<0.001)$. cTnI and cTnT remained undetectable, while NT-proBNP levels marginally increased to $88.3 \mathrm{pg} / \mathrm{mL}$.

Six of 18 patients had an increase or no change in LVEF (range $0-8.0 \%$ ). The remaining 12 patients had a median decline in LVEF after treatment of $4.5 \%$ (range $2.0 \%-20.0 \%$ ).

Table I Baseline and follow-up cardiac biomarkers of all patients

\begin{tabular}{llll}
\hline & \multicolumn{1}{l}{ Baseline } & At follow-up & Change \\
\cline { 2 - 4 } & \multicolumn{1}{l}{ Median (25th, 75th percentiles) } \\
\hline $\mathrm{cTnl}(\mathrm{ng} / \mathrm{mL})$ & $0.00(0.00,0.01)$ & $0.05(0.01,0.09)$ & $0.04(0.00,0.08)$ \\
$\mathrm{cTnT}(\mathrm{ng} / \mathrm{mL})$ & $0.00(0.00,0.00)$ & $0.00(0.00,0.00)$ & $0.00(0.00,0.00)$ \\
$\mathrm{CKMB}(\mathrm{ng} / \mathrm{mL})$ & $0.80(0.50,0.80)$ & $1.00(0.70,1.50)$ & $0.40(0.00,0.90)$ \\
$\mathrm{NT}-\mathrm{proBNP}$ & 46.10 & 88.30 & 20.50 \\
$(\mathrm{pg} / \mathrm{mL})$ & $(34.10,106.10)$ & $(67.80,135.90)$ & $(-11.50,88.00)$ \\
$\mathrm{hscTnT}(\mathrm{pg} / \mathrm{mL})$ & 1.39 & 19.10 & 16.90 \\
& $(0.00,3.36)$ & $(5.90,28.70)$ & $(4.10,25.60)$ \\
Pre-MUGA EF $(\%)$ & 58.00 & 58.00 & -3.00 \\
& $(56.00,58.00)$ & $(53.00,65.00)$ & $(-6.00,4.00)$ \\
\hline
\end{tabular}

Abbreviations: $\mathrm{CTnl}$, cardiac troponin I; cTnT, cardiac troponin T; CKMB, creatine kinase MB; NT-proBNP, N-terminal pro-B-type natriuretic peptide; hscTnT, high-sensitivity cTnT; MUGA, multigated acquisition (equilibrium radionuclide ventriculography); EF, ejection fraction. 
The 12 subjects with a decline in LVEF ( $n=12$, median LVEF after chemotherapy 54\%) were compared to those with no change in LVEF ( $n=6$, median LVEF after chemotherapy 64\%). Those who experienced a decline in LVEF had higher baseline hscTnT levels in comparison to those who had had no change in LVEF $(2.7 \mathrm{pg} / \mathrm{mL}, 0.1 \mathrm{pg} / \mathrm{mL}$, respectively; $P=0.07$ ) (Table 2). Baseline TnT, TnI, and NT-proBNP were not associated with a decline in LVEF. Spearman correlation demonstrated that patients with a higher baseline hscTnT and creatine kinase MB tended to have a greater decline in LVEF (Spearman correlation $-0.54,95 \%$ confidence interval -0.80 to -0.08 [ $P=0.02]$, and $-0.49,95 \%$ confidence interval -0.77 to $-0.01[P=0.04]$, respectively). Baseline TnT, TnI, and NT-proBNP were not associated with a decline in LVEF. Change in TnT, TnI, and NT-proBNP and hscTnT were not associated with a decline in LVEF. No subjects developed clinical symptoms of heart failure. No subjects had other identifiable causes of cardiomyopathy, myocardial inflammatory disease, or shock.

\section{Discussion}

The optimal treatment for chemotherapy-induced cardiomyopathy is prevention. Biomarkers allow individuals at risk for developing long-term cardiac complications to be identified, in many cases before any other clinical evidence is apparent. In our study, we enrolled 18 individuals receiving anthracycline-based chemotherapy. Those individuals with a higher baseline hscTnT were more likely to have a decline in LVEF. While none of these patients developed symptomatic cardiac failure or a decline in their LVEF to below the lower limits of normal, there was a suggestion that those individuals with an elevated baseline hscTnT were more likely to have a significant decline in their LVEF. Declines in LVEF can predispose these subjects to early cardiac failure. While hscTnT can increase for such reasons as dilated cardiomyopathy, myocardial inflammatory disease, and shock, none of

Table 2 Baseline characteristics stratified by change in EF

\begin{tabular}{lllll}
\hline Variable & & \multicolumn{2}{l}{$\begin{array}{l}\text { No change in EF } \\
\text { decline in EF }\end{array}$} & P-value \\
\cline { 5 - 5 } Baseline & & Median & Median & \\
\hline cTnl $(\mathrm{ng} / \mathrm{mL})$ & & 0 & 0 & 0.48 \\
$\mathrm{cTnT}(\mathrm{ng} / \mathrm{mL})$ & & 0 & 0 & 1.00 \\
CKMB $(\mathrm{ng} / \mathrm{mL})$ & & 0.7 & 0.8 & 0.25 \\
NTT-proBNP $(\mathrm{pg} / \mathrm{mL})$ & & 71.4 & 45.5 & 0.61 \\
hscTnT $(\mathrm{pg} / \mathrm{mL})$ & & 0.1 & 2.7 & 0.07 \\
\hline
\end{tabular}

Abbreviations: $\mathrm{cTnl}$, cardiac troponin l; $\mathrm{cTnT}$, cardiac troponin T; CKMB, creatine kinase MB; NT-proBNP, N-terminal pro-B-type natriuretic peptide; hscTnT, highsensitivity $\mathrm{CTnT}$; EF, ejection fraction. our subjects had any other symptoms or history to explain the change in hscTnT other than the receipt of chemotherapy and cardiac injury.

The results of our study are supported by the work of others in both cancer patients and noncancer patients. In noncancer patients, detectable TnI and TnT concentrations have been associated with cardiac failure and were an independent risk factor for cardiac death. ${ }^{8,10,11}$ Daniels et al found that detectable TnT (with a threshold of $0.01 \mathrm{ng} / \mathrm{mL}$ ) was associated with increased risk of death (hazard ratio $1.85, P<0.001$ ) in 957 elderly adults (mean age 77 years at baseline). ${ }^{8}$ Looking at cancer patients, Sawaya et al evaluated the usefulness of hscTnI by looking at values at baseline and 3 and 6 months after chemotherapy with anthracyclines and trastuzumab. hscTnI remained elevated in $28 \%$ of patients. ${ }^{12}$ Detectable hscTnI at 3 months was an independent predictor of developing cardiac dysfunction. While the study by Sawaya et al demonstrated an association between elevations in hscTnT after chemotherapy and a decline in LVEF, our study suggests that individuals with elevated hscTnT at baseline are more likely to have a decline in LVEF. ${ }^{12}$ Given that elevations in hscTnT have been associated with structural and functional measures of heart disease, it is biologically plausible that individuals with elevated levels of baseline hscTnT levels and levels after treatment may both suggest these subgroups are at higher risk of developing chemotherapy-induced cardiomyopathy.

Our study is limited by its small sample size. Published literature suggests asymptomatic declines in LVEF may occur in up to $30 \%$ of individuals receiving chemotherapy for breast cancer and/or lymphoma, and it is possible that our small sample size did not allow for a sample large enough to detect this difference. This study, however, is hypothesisgenerating. It suggests that further work should be performed in investigating the utility of baseline cardiac biomarkers in predicting cardiac changes in LVEF. Longer follow-up may allow for better correlation of how these values predict changes in clinical outcome.

Cardiac complications from chemotherapy remain a serious adverse effect of chemotherapy, particularly with anthracycline-based regimens. Early detection with the use of biomarkers remains crucial in evaluating these patients, and in potentially introducing interventions to prevent these long-term complications. Screening individuals who are going to receive anthracyclines with hscTnT may be indicated. Larger, prospective clinical trials are warranted. The results of one such ongoing trial (MANTICORE) are highly anticipated..$^{13,14}$ 


\section{Acknowledgments}

This research was supported in part by the National Institutes of Health Building Interdisciplinary Research Careers in Women's Health (NIH K12-HD055887) and the National Institutes of Health (grant P30-CA77598), using the shared resource of the Biostatistics Core, Masonic Cancer Center, University of Minnesota.

\section{Disclosure}

The authors report no conflicts of interest in this work.

\section{References}

1. Lenihan DJ, Cardinale DM. Late cardiac effects of cancer treatment. J Clin Oncol. 2012;30(30):3657-3664.

2. McKillop J, Bristow M, Goris M, Billingham M, Bockemuehl K. Sensitivity and specificity of radionuclide ejection fractions in doxorubicin cardiotoxicity. Am Heart J. 1983;106(5 Pt 1):1048-1056.

3. Lenihan DJ, Cardinale D, Cipolla CM. The compelling need for a cardiology and oncology partnership and the birth of the International CardiOncology Society. Prog Cardiovasc Dis. 2010;53(2):88-93.

4. Neeland IJ, Drazner MH, Berry JD, et al. Biomarkers of chronic cardiac injury and hemodynamic stress identify a malignant phenotype of left ventricular hypertrophy in the general population. $J$ Am Coll Cardiol. 2013;61(2):187-195.

5. Kalogeropoulos AP, Georgiopoulou VV, deFilippi CR, Gottdiener JS, Butler J. Echocardiography, natriuretic peptides, and risk for incident heart failure in older adults: the Cardiovascular Health Study. JACC Cardiovasc Imaging. 2012;5(2):131-140.

6. de Antonio M, Lupon J, Galan A, Vila J, Urrutia A, Bayes-Genis A. Combined use of high-sensitivity cardiac troponin $\mathrm{T}$ and $\mathrm{N}$-terminal pro-B type natriuretic peptide improves measurements of performance over established mortality risk factors in chronic heart failure. Am Heart J. 2012;163(5):821-828.
7. Hsieh BP, Rogers AM, Na B, Wu AH, Schiller NB, Whooley MA. Prevalence and prognostic significance of incidental cardiac troponin $T$ elevation in ambulatory patients with stable coronary artery disease: data from the Heart and Soul study. Am Heart J. 2009;158(4):673-679.

8. Daniels LB, Laughlin GA, Clopton P, Maisel AS, Barrett-Connor E. Minimally elevated cardiac troponin $\mathrm{T}$ and elevated $\mathrm{N}$-terminal proB-type natriuretic peptide predict mortality in older adults: results from the Rancho Bernardo study. J Am Coll Cardiol. 2008;52(6): $450-459$.

9. Cardinale D, Colombo A, Sandri MT, et al. Prevention of highdose chemotherapy-induced cardiotoxicity in high-risk patients by angiotensin-converting enzyme inhibition. Circulation. 2006;114(23): 2474-2481.

10. Zethelius B, Johnston N, Venge P. Troponin I as a predictor of coronary heart disease and mortality in 70-year-old men: a community-based cohort study. Circulation. 2006;113(8):1071-1078.

11. Latini R, Masson S, Anand IS, et al. Prognostic value of very low plasma concentrations of troponin $\mathrm{T}$ in patients with stable chronic heart failure. Circulation. 2007;116(11):1242-1249.

12. Sawaya H, Sebag IA, Plana JC, et al. Early detection and prediction of cardiotoxicity in chemotherapy-treated patients. Am J Cardiol. 2011;107(9):1375-1380.

13. Bosch X, Esteve J, Sitges M, et al. Prevention of chemotherapy-induced left ventricular dysfunction with enalapril and carvedilol: rationale and design of the OVERCOME trial. J Card Fail. 2011;17(8):643-648.

14. Pituskin E, Haykowsky M, Mackey JR, et al. Rationale and design of the Multidisciplinary Approach to Novel Therapies in Cardiology Oncology Research trial (MANTICORE 101 - breast): a randomized, placebo-controlled trial to determine if conventional heart failure pharmacotherapy can prevent trastuzumab-mediated left ventricular remodeling among patients with HER2+ early breast cancer using cardiac MRI. BMC Cancer. 2011;11:318.
Vascular Health and Risk Management

\section{Publish your work in this journal}

Vascular Health and Risk Management is an international, peerreviewed journal of therapeutics and risk management, focusing on concise rapid reporting of clinical studies on the processes involved in the maintenance of vascular health; the monitoring, prevention and treatment of vascular disease and its sequelae; and the involvement of

\section{Dovepress}

metabolic disorders, particularly diabetes. This journal is indexed on PubMed Central and MedLine. The manuscript management system is completely online and includes a very quick and fair peer-review system, which is all easy to use. Visit http://www.dovepress.com/ testimonials.php to read real quotes from published authors. 